\title{
Convenciones de transcripción
}

\begin{tabular}{|c|c|}
\hline Símbolo & \\
\hline $\begin{array}{l}\text { (\# de } \\
\text { segundos) }\end{array}$ & $\begin{array}{l}\text { n número entre paréntesis indica la duración, en segundos, de una pausa en } \\
\text { I habla. (0.3) (2.3) }\end{array}$ \\
\hline (.) & dica una pausa breve, normalmente menos que 0.2 segundos. \\
\hline [ texto ] & dica el principio y el final de solapamiento entre hablantes. \\
\hline$=$ & sin interrupción. \\
\hline$\uparrow$ & bida marcada de entonación. \\
\hline$\downarrow$ & rcada de entonación. \\
\hline ¿? & ta. \\
\hline$>$ texto< & $\begin{array}{l}\text { ue el texto entre los símbolos se dijo de una forma más rápida de lo } \\
\text { l. }\end{array}$ \\
\hline$\langle$ texto〉 & $\begin{array}{l}\text { dica que el texto entre los símbolos se dijo de una forma más lenta de lo } \\
\text { bitual. }\end{array}$ \\
\hline$:::$ & $\begin{array}{l}\text { el sonido inmediatamente anterior. Mientras más dobles } \\
5 \text { mayor la extensión del alargamiento. }\end{array}$ \\
\hline $\begin{array}{l}\text { "texto/ } \\
\text { palabra" }\end{array}$ & $\begin{array}{l}\text { S oraciones entre comillas indican que estas fueron producidas con una } \\
\text { tonación que denota estilo directo. }\end{array}$ \\
\hline hh. & dible \\
\hline.$h h$ & \\
\hline${ }^{\circ}$ palabra ${ }^{\circ}$ & $\begin{array}{l}\text { S símbolos de graduación indican susurro o expresiones más silenciosas } \\
\text { de el resto. }\end{array}$ \\
\hline @@ & isa. Mientras más arrobas, más larga es la risa. \\
\hline @palabra@ & Palabras entre las arrobas indican risa infiltrada en la producción lingüística. \\
\hline Pala- & I guión muestra la interrupción brusca de una palabra. \\
\hline PALABRA/ & Las mayúsculas indican grito o volumen más alto que el resto de la producción \\
\hline TEXTO & \\
\hline $\begin{array}{l}\text { (texto/ } \\
\text { palabra) }\end{array}$ & $\begin{array}{l}\text { Fragmento del que se tienen dudas. Se escribe entre paréntesis lo que se cree } \\
\text { haber oído. }\end{array}$ \\
\hline $\begin{array}{l}(. .) \\
((\text { cursiva }))\end{array}$ & $\begin{array}{l}\text { Fragmento incomprensible. Se puede acompañar de especificación de tiempo. } \\
\text { Anotación de actividad no verbal. También precede observaciones prosódicas. }\end{array}$ \\
\hline
\end{tabular}

Nota: Convenciones basadas en las normas de transcripción propuestas por Jefferson:

Jefferson Gail (1984). On the organization of laughter in talk about troubles. En J. Maxwell Atkinson \& John Heritage (eds.), Structures of Social Action: Studies in Conversation Analysis (pp. 346-369). Cambridge: Cambridge University Press. 
